\title{
Editorial
}

\section{Promotion of Scientific Temper}

\section{Rajeev Gupta}

Editor, RUHS Journal of Health Sciences, Rajasthan University of Health Sciences, Jaipur.

In recent decades Indian universities have relegated themselves to focus on administrative issues. Most of the universities in India focus on the mundane such as creating new departments, appointments of faculty, conduct of examinations, etc. We believe that creation of scientific temper among the students and faculty is the primary objective of a university.

Wikipedia defines scientific temper as a way of life. In this context, it has been defined as an individual and social process of thinking and acting, which uses the scientific method and which may consequently include questioning, observing physical reality, testing, hypothesizing, analyzing and communicating. Scientific temper, thus, describes an attitude that involves the application of logic. Discussion, argument and analysis are vital parts of scientific temper. Elements of fairness, equality and democracy are built into it.

Jawaharlal Nehru was the first to use the phrase in 1946. He later gave a descriptive explanation of this term: "... what is needed is the scientific approach, the adventurous and yet critical temper of science, the search for truth and new knowledge, the refusal to accept anything without testing and trial, the capacity to change previous conclusions in the face of new evidence, the reliance on observed fact and not on pre-conceived theory, the hard discipline of the mind. All this is necessary, not merely for the application of science but for life itself and the solution of its many problems."
Scientific temper has also been defined as the mental attitude that is behind the method of acquiring reliable and practical knowledge, not accepting answers without testing and trial, requiring solid information and incontrovertible data and suitable analysis before accepting anything. It is also not accepting views and opinions simply because traditionally they have accepted these views, not observing obscurantist and superstitious practices and openness of mind and absence of dogmatism. The RUHS Journal of Health Sciences shall foster all these virtues of to facilitate scientific temper.

Centuries ago, Henry Power writing in his book Experimental Philosophy (1664), describes scientific inventions (philosophy) as:" "This is the age wherein (me-thinks) philosophy comes in with a spring-tide; and the Peripateticks may as well hope to stop the current of the tide, or to fetter the ocean, as hinder the overflowing of free philosophy. $\mathrm{Me}$ thinks, I see how all the old rubbish must be thrown away, and the rotten buildings be overthrown, and carried away with so powerful an inundation. These are the days that must lay a new foundation of a more magnificent philosophy, never to be overthrown: that will empirically and sensibly canvass the Phaenomena of Nature, deducing the causes of things from such originals in Nature, as we observe are producible by Art, and the infallible demonstration of Mechanicks; and certainly, this is the way, and no other, to build a true and permanent 
Philosophy....." Surprisingly the old philosophy (science) perpetuated by peripatetics is still persisting in many forms in current healthcare.

The RUHS Journal of Health Sciences aims to publish science that evaluates old philosophies in the present context and describes them scientifically. The focus of the Journal shall be to encourage medical students and faculty to communicate locally important problems in form of reviews, original articles and short articles. For this we would encourage writings on area-specific, state specific as well as national and international health problems. We shall focus not only on pure medical scientific problems but also on environmental, social, economic and psychological determinants of health.

\section{REFERENCES}

1. Wikipedia. Scientific temper. Available at: https://en.wikipedia.org/wiki/Scientific_temper .Accessed 27 November 2016.

2. Wootton D. Introduction. In: The Invention of Science: A New History of Scientific Revolution. London. Penguin Books. 2015; 1-2. 